\title{
How to Strengthen Co-operation among Developing Countries
}

\section{Paul Streeten}

Solidarity between developing countries is an important condition for their joint exercise of bargaining power. But solidarity is difficult to achieve. The reason for this is best illustrated by the case of a restrictive, price-raising cartel of primary product exporters, but it applies with equal force to other exercises of joint bargaining power, such as the threat to expropriate foreign investments, the threat to default on debts, limitations on repatriation of foreign capital and profits, the threat of the withdrawal of money balances, joint action to improve the terms of contracts with multinationals (e.g. the withdrawal of tax concessions), refusal to sign patent or copyright conventions, denial of overflying rights, nonco-operation in the control of drug-growing and drug-traffic, and many others.

Solidarity is difficult to achieve because the more effective a cartel or a cartel-like agreement, the greater is the reward for any one member to break it. But the fear that anyone may break the agreement will induce those who would otherwise be willing to adhere, to prepare for the break-up. For sticking to an agreement while others abandon it makes the loyal members worse off than they would have been without any agreement. The potential defectors cherish the hope of operating outside the agreement. But this encourages on the part of the conformers the fear of a situation without the agreement. This fear is ever-present, even if there are no actual or potential defectors. The fear itself leads to actions that undermine the agreement. Action outside the agreement is an ever-present hope and action without the agreement an ever-present threat.

Those emphasizing solidarity, joint actions, common fronts, which give rise to such unstable situations should, therefore, pay attention to instituting a system of rewards and penalties that shifts the incentive so as to make the unstable solution stable.

An important source of rewards in commodity agreements are diversification funds and technical assistance to diversification. These have a double virtue. First, they compensate countries for restricting supplies and, secondly, where opportunity costs are positive, they absorb resources in alternative uses, thereby reducing the danger of erosion of the cartel. Through geographical and commodity diversification countries previously dependent on one or a few markets and one or a few crops or minerals or services can thereby be made more self-reliant and their loyalty to the cartel increased.

Another factor that will enhance the stability of the cartel is the ability of a supplier to do without any earnings, or with substantially reduced earnings, for a period. (This is one of the forces that strengthens OPEC.) Withholding supplies is a powerful weapon of the cartel. If a supplying country is not able to withhold supplies because it depends on earnings, the cartel can be strengthened by other members (of this cartel or of some other agreement) compensating the country for withholding supplies.

It is suggested here that more thought should be given to the provision of powerful incentives, both rewards and penalties, which would make defection less attractive and therefore reduce the fear of defection by others. Relevant considerations in devising such a system of incentives will be: fair sharing with due regard for the needs of the poorest; reconciling differences in preferences for the distribution of net gains over time; differences in current and future costs of production and in the ability to hold reserves; and others. 